\title{
Growth mode-dependent ferromagnetic properties of palladium nanoclusters
}

\author{
Venäläinen, A.
}

2018-07-21

Venäläinen , A , Jalkanen , P , Tuboltsev , V , Savin , A \& Räisänen , J 2018 , ' Growth mode-dependent ferromagnetic properties of palladium nanoclusters ' , Journal of Applied Physics , vol. 124 , no. 3 , 033904 . https://doi.org/10.1063/1.5022364

http://hdl.handle.net/10138/308526

https://doi.org/10.1063/1.5022364

unspecified

publishedVersion

Downloaded from Helda, University of Helsinki institutional repository.

This is an electronic reprint of the original article.

This reprint may differ from the original in pagination and typographic detail.

Please cite the original version. 


\section{Growth mode-dependent ferromagnetic properties of palladium nanoclusters}

Cite as: J. Appl. Phys. 124, 033904 (2018); https://doi.org/10.1063/1.5022364

Submitted: 14 January 2018 . Accepted: 04 July 2018. Published Online: 20 July 2018

A. Venäläinen, P. Jalkanen, V. Tuboltsev, A. Savin (D), and J. Räisänen
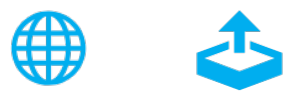

Export Citation

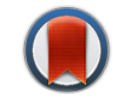

View Online

\section{ARTICLES YOU MAY BE INTERESTED IN}

Electromagnetic properties of the Great Pyramid: First multipole resonances and energy concentration

Journal of Applied Physics 124, 034903 (2018); https://doi.org/10.1063/1.5026556

Modeling the photo-induced inverse spin-Hall effect in $\mathrm{Pt} /$ semiconductor junctions

Journal of Applied Physics 124, 033902 (2018); https://doi.org/10.1063/1.5037653

Perspective: Magnetoresistive sensors for biomedicine

Journal of Applied Physics 124, 030902 (2018); https://doi.org/10.1063/1.5027035
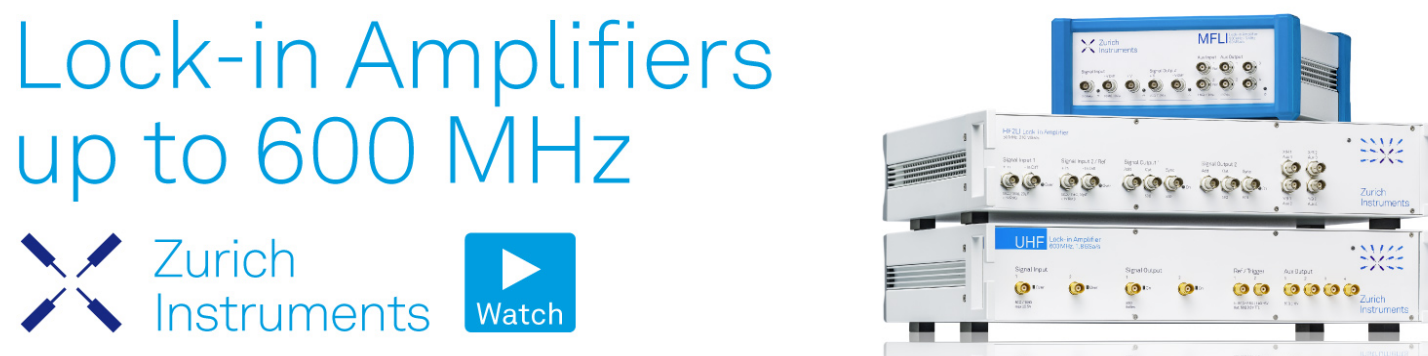


\title{
Growth mode-dependent ferromagnetic properties of palladium nanoclusters
}

\author{
A. Venäläinen, ${ }^{1}$ P. Jalkanen, ${ }^{1}$ V. Tuboltsev,${ }^{1}$ A. Savin, ${ }^{2}$ and J. Räisänen ${ }^{1, a)}$ \\ ${ }^{1}$ Division of Materials Physics, Department of Physics, University of Helsinki, P.O. Box 43, \\ FIN-00014 Helsinki, Finland \\ ${ }^{2}$ Low Temperature Laboratory, Department of Applied Physics, Aalto University School of Science, \\ P.O. Box 15100, FI-00076 Aalto, Finland
}

(Received 14 January 2018; accepted 4 July 2018; published online 20 July 2018)

\begin{abstract}
Cluster deposited Pd films exhibit ferromagnetism in the temperature range from 1.8 to $400 \mathrm{~K}$. The magnetization properties are found to be dependent on the film thickness. The varying morphology of the resulting $\mathrm{Pd}$ film with respect to thickness suggests that cluster size, deposition energy, and substrate type are crucial for the resulting film magnetization. This is demonstrated by the characteristic ferromagnetic hysteresis with the temperature dependent saturation magnetization, remanence, and coercivity of palladium nanocluster aggregates. The temperature dependence of the saturation magnetization, remanence, and coercivity of Pd nanoclusters were measured using an ultra-highsensitive magnetometer based on a superconducting quantum interference device, and the morphology of the samples was analyzed by tunneling electron microscopy. Published by AIP Publishing.

https://doi.org/10.1063/1.5022364
\end{abstract}

\section{INTRODUCTION}

Palladium is a paramagnetic metal as a bulk. When going down to nanoscale, the surface to volume ratio increases and gives rise to size-dependent properties. Both experimental and theoretical studies indicate a ferromagnetic behaviour in low dimensional Pd systems, such as thin films, ${ }^{1-7}$ nanowires, ${ }^{8,9}$ a few nanometer size clusters, ${ }^{10-12}$ grain and twin boundaries, ${ }^{11,13}$ reduced or unsaturated coordination of surface atoms, ${ }^{10}$ and the expansion of lattice spacings. ${ }^{14}$

Stable ferromagnetism in metals sets in when the Stoner criterion $I D\left(\epsilon_{F}\right)>1$ is fulfilled, $I$ is the exchange integral, and $D\left(\epsilon_{F}\right)$ is the density of states at Fermi energy $\epsilon_{F} \cdot{ }^{15} \mathrm{Pd}$ has a large Stoner factor of $0.873 .{ }^{16} \mathrm{As} \mathrm{Pd}$ is considered to be on the threshold of ferromagnetism and it has shown ferromagnetic tendencies, interest has been drawn to investigate the factors that cause Pd to fulfill the Stoner criterion. The increase in the ferromagnetic behaviour in nanoparticles (NPs) is related to the increase in the density of states at the Fermi level due to a small fraction of atoms located near the twin boundaries ${ }^{11}$ or due to strain and changes in the crystal symmetry of the system. ${ }^{17}$ Due to its relatively large $D\left(\epsilon_{F}\right)$, $\mathrm{Pd}$ is a candidate as a material for realizing switching of magnetism with external controls, such as charging and strain, as the magnetism exhibited by $\mathrm{Pd}$ is very sensitive to the changes in atomic structure and environment. ${ }^{18}$

Ferromagnetism in bare $\mathrm{Pd}$ fine particles was first reported by Tanyama et al. in $1997,{ }^{19}$ since then others have also reported similar findings, ${ }^{10,14,17,20-26}$ see Table I for a literature survey of magnetic characterization of bare $\mathrm{Pd}$ nanoparticles. What exactly gives rise to the occurrence of magnetism at the nanoscale in otherwise nonmagnetic materials is still not answered; it is thought to originate from unstable surface atoms in nanosized particles and it has been

${ }^{\text {a)} E l e c t r o n i c ~ m a i l: ~ j y r k i . r a i s a n e n @ h e l s i n k i . f i ~}$ proposed $^{10,14,19}$ to be associated with the top few atomic layers in (100) facets.

For details about the different theoretical approaches related to the magnetic properties in Pd atomic clusters, we refer to the article of Aguilera-Granja et al. ${ }^{27}$ The different available theoretical reports predict that the ferromagnetism in Pd could possibly arise due to surface effects, ${ }^{13}$ hcp crystal structure, ${ }^{13}$ crystal defects, ${ }^{13}$ lattice expansion, ${ }^{28,29}$ or icosahedral structure. ${ }^{12}$ Thereby, there is a clear link between the ferromagnetic property of $\mathrm{Pd}$ at the nanoscale and prevailing defects. ${ }^{30}$

As stated above, the magnetic phenomena in $\mathrm{Pd}$ nanoparticles are very sensitive to the atomic environment. Thereby, we have investigated how the magnetic behaviour of $\mathrm{Pd}$ nanoclusters varies due to changes in range and degree of interactions. When clusters are apart (below the percolation threshold), long range dipolar forces and short range exchange forces act in-between them. As particles come in contact with each other due to agglomeration, exchangecoupled agglomerates will be produced. These agglomerates interact with each other via dipolar forces. As the percolation threshold is exceeded, the behaviour of cluster assemblies will be dominated by inter-cluster exchange coupling. ${ }^{33}$ The exchange interaction at the boundaries between particles is weaker than the intra-particle atomic exchange which further reinforces the image of separate but interacting clusters. ${ }^{34}$ Thereby, it is of interest to see how the magnetization of the ferromagnetic Pd clusters evolves as they start to interact. Contrary to the gold clusters, ${ }^{35}$ a clear systematic cluster size dependent magnetism has not yet been reported for Pd. The condensate $\mathrm{Pd}$ clusters are likely to contain defects and strain, responsible for the itinerant Pd cluster magnetisation as reported by Oba et al. ${ }^{17,22,24}$

Our Pd samples have been stored under ambient conditions in order to undergo natural oxidation. Previous experiments have either been done in vacuum or the samples have been exposed to $\mathrm{O}_{2}$ gas. The exposure to $\mathrm{O}_{2}$ gas has been 
TABLE I. Literature survey of magnetic characterization of bare Pd nanoparticles. ${ }^{\text {a }}$

\begin{tabular}{|c|c|c|c|c|c|c|c|c|}
\hline $\begin{array}{l}\text { Pd form } \\
\text { (preparation) }\end{array}$ & $\begin{array}{l}\text { Nanoparticle } \\
\text { diameter (nm) }\end{array}$ & Oxidation & $\begin{array}{c}\mathrm{T} \\
(\mathrm{K})\end{array}$ & $\begin{array}{l}\mu_{S} \times 10^{-3} \\
\left(\mu_{B} / \text { atom }\right)\end{array}$ & $\begin{array}{c}\mathrm{M}_{S} \\
\left(\mathrm{emu} / \mathrm{cm}^{3}\right)\end{array}$ & $\begin{array}{c}\mathrm{M}_{R} \\
\left(\mathrm{emu} / \mathrm{cm}^{3}\right)\end{array}$ & $\begin{array}{l}\mathrm{H}_{C} \\
(\mathrm{Oe})\end{array}$ & Reference \\
\hline \multirow[t]{3}{*}{ NP (seed-mediated growth) } & $12 \pm 3$ & & 5 & & & $0.032^{\mathrm{b}}$ & $77.5^{\mathrm{b}}$ & 26 \\
\hline & 7.7 & & 5 & & & $0.049^{\mathrm{b}}$ & $40^{\mathrm{b}}$ & \\
\hline & 7.7 & & 300 & & & & 100 & \\
\hline \multirow[t]{5}{*}{ NP (gas evaporation) } & $19.9 \pm 0.6$ & exposed & & $0.57 \pm 0.06^{\mathrm{b}}$ & $0.36 \pm 0.04$ & & & 17 \\
\hline & $34.1 \pm 1.3$ & to $\mathrm{O}_{2}$ & & $8.76 \pm 0.02^{\mathrm{b}}$ & $5.53 \pm 0.01$ & & & \\
\hline & $31.0 \pm 3.6$ & & & $7.46 \pm 0.10^{\mathrm{b}}$ & $4.71 \pm 0.06$ & & & \\
\hline & $30.0 \pm 2.0$ & & & $19.71 \pm 0.10^{\mathrm{b}}$ & $12.44 \pm 0.06$ & & & \\
\hline & $23.9 \pm 2.0$ & & & $21.95 \pm 0.22^{\mathrm{b}}$ & $13.85 \pm 0.14$ & & & \\
\hline NP (mechanical milling) & 5.5 & & 300 & $1.4^{\mathrm{b}}$ & $0.8777^{\mathrm{b}}$ & $0.003^{\mathrm{b}}$ & $6.25^{\mathrm{b}}$ & 23 \\
\hline \multirow[t]{4}{*}{ NP (gas evaporation) } & 20 & & 5 & $14.29^{\mathrm{b}}$ & $9.02^{\mathrm{b}}$ & & & 21 \\
\hline & & & 400 & $11.43^{\mathrm{b}}$ & $7.21^{\mathrm{b}}$ & & & \\
\hline & & exposed & 5 & $1.14^{\mathrm{b}}$ & $0.72^{\mathrm{b}}$ & & & \\
\hline & & to $\mathrm{O}_{2}$ & 400 & $0.95^{\mathrm{b}}$ & $0.60^{\mathrm{b}}$ & & & \\
\hline \multirow[t]{4}{*}{ NP (gas evaporation) } & 23 & & 1.8 & $16.8^{\mathrm{b}}$ & $10.21^{\mathrm{b}}$ & & & 10 \\
\hline & & & 400 & $14.75^{\mathrm{b}}$ & $9.31^{\mathrm{b}}$ & & & \\
\hline & 16 & & 5 & $16.8 \pm 0.4$ & & & & \\
\hline & 21.6 & $\begin{array}{l}\text { exposed } \\
\text { to } \mathrm{O}_{2}\end{array}$ & 400 & $4.77^{\mathrm{b}}$ & $3.01^{\mathrm{b}}$ & & & \\
\hline \multirow[t]{2}{*}{ NP (gas evaporation) } & 11.8 & & 1.8 & $11.9^{\mathrm{b}}$ & $7.5^{\mathrm{b}}$ & & & 20 \\
\hline & 14.4 & & 1.8 & $7.1^{\mathrm{b}}$ & $4.5^{\mathrm{b}}$ & & & \\
\hline NP (gas evaporation) & 11.8 & & & $230 \pm 190$ & & & & 19 \\
\hline \multirow[t]{4}{*}{$\mathrm{NP}$ (supported by mesoporous $\mathrm{Si}$ ) } & $29.3 \pm 6.26$ & & 5 & $6.80^{\mathrm{b}}$ & $4.29^{\mathrm{b}}$ & & & 31 \\
\hline & & & 40 & $16.34^{\mathrm{b}}$ & $10.31^{\mathrm{b}}$ & & & \\
\hline & & & 80 & $14.29^{\mathrm{b}}$ & $9.02^{\mathrm{b}}$ & & & \\
\hline & & & 150 & $10.21^{\mathrm{b}}$ & $6.44^{\mathrm{b}}$ & & & \\
\hline \multirow[t]{2}{*}{ NP (in solution) } & 4 & & 5 & 3.8 & & $0.0457 \pm 0.0004$ & $150 \pm 4$ & 14 \\
\hline & & & 200 & & & $0.0369 \pm 0.0004$ & $87 \pm 4$ & \\
\hline NP (calculated value) & & & & 120 & & & & 32 \\
\hline Pd bilayer & & & & 170 & & & & 6 \\
\hline
\end{tabular}

${ }^{\mathrm{a}}$ For comparison, original magnetization data are expressed in $\mathrm{emu}^{-3}$ assuming bulk palladium density $\left(12.023 \mathrm{~g} \mathrm{~cm}^{-3}\right)$.

${ }^{b}$ Values derived from data presented in the manuscript.

done in order to suppress the surface ferromagnetism prior the magnetic measurements, in order to focus only on internal magnetism. On an average, $8 \%$ of the total magnetization is left compared with the samples that have been held in vacuum. ${ }^{10,21,24}$ Hence, the surface magnetization of our Pd cluster films is expected to be suppressed by oxidation in an ambient atmosphere.

\section{EXPERIMENTAL}

In this work, palladium clusters were produced with a condensation-cell-type cluster aggregation source (NC200, Oxford Applied Research), charged with a Pd target of 99.99\% purity. The clusters were deposited in an ultra-high vacuum at room temperature directly on a template, a lightweight homogenous plastic straw provided by Quantum Design as a sample holder for ultra-high-sensitivity measurements. The clusters are formed when $\mathrm{Pd}$ atoms agglomerate in argon gas (flow rate: $16 \mathrm{sccm}$ ). The kinetic energy $\mathrm{E}_{C}$ of the $\mathrm{Pd}$ clusters can be approximated to be $<0.16 \mathrm{eV}$ per atom, according to $\mathrm{E}_{C}=0.5 \mathrm{NM}_{C} \mathrm{v}_{C}^{2}$ and the cluster velocity $\mathrm{v}_{C}$ being close to the expanding gas velocity, ${ }^{36} \mathrm{v}_{C}=\mathrm{v}_{A r}$ $=\left[2 k_{B} T \gamma /(\gamma-1) m_{A r}\right]^{1 / 2}$, where $\gamma$ is the heat capacity ratio for argon and equal to $5 / 3, \mathrm{k}_{B}$ is the Boltzmann constant, $\mathrm{T}$ is the gas temperature, and $\mathrm{m}_{A r}$ is the atomic weight for argon. $^{37}$

The magnetic properties were evaluated using an ultrahigh-sensitive magnetometry based on a superconducting quantum interference device, SQUID (Quantum Design MPMS-XL7), providing a magnetic field up to $70 \mathrm{kOe}$ at temperatures from 1.8 to $400 \mathrm{~K}$. As the level of magnetic response from the palladium samples was expected to be low, the background signal caused by the templates (without any palladium deposited) was checked before the actual SQUID measurements of the palladium nanoparticles. The background signal measurements were performed on the template with all experimental conditions configured as in the actual measurements. The resulting data were then subtracted from the actual measured magnetization data.

To prevent the deposited palladium as well as the template to be exposed to parasitic magnetic impurities, special care was taken of purity in the experiments. To ensure that the effect from impurities on the acquired results is negligible, the impurity level was checked by elastic recoil 
detection analysis (ERDA), after the magnetization measurements.

The morphology of the samples was examined by highresolution transmission electron microscopy, HR-TEM (JEOL JEM-2200FS). For the HR-TEM measurements, the palladium clusters were deposited on carbon holey films $\sim 12 \mathrm{~nm}$ thick (Quantifoil Micro Tools $\mathrm{GmbH}$ ). We assume that the morphology of the deposited palladium was not affected by the templates, as both the Quantifoil carbon film and the material for the plastic straws used in the magnetization measurements are chemically nonreactive.

\section{RESULTS AND DISCUSSION}

Based on the rigorous image analysis of HR-TEM micrographs, similar to those presented in Fig. 1, about $6.8 \pm 0.7 \%$ of the surface area of the $1 \mathrm{~min}$ deposited sample was covered with Pd clusters, with an average cross-
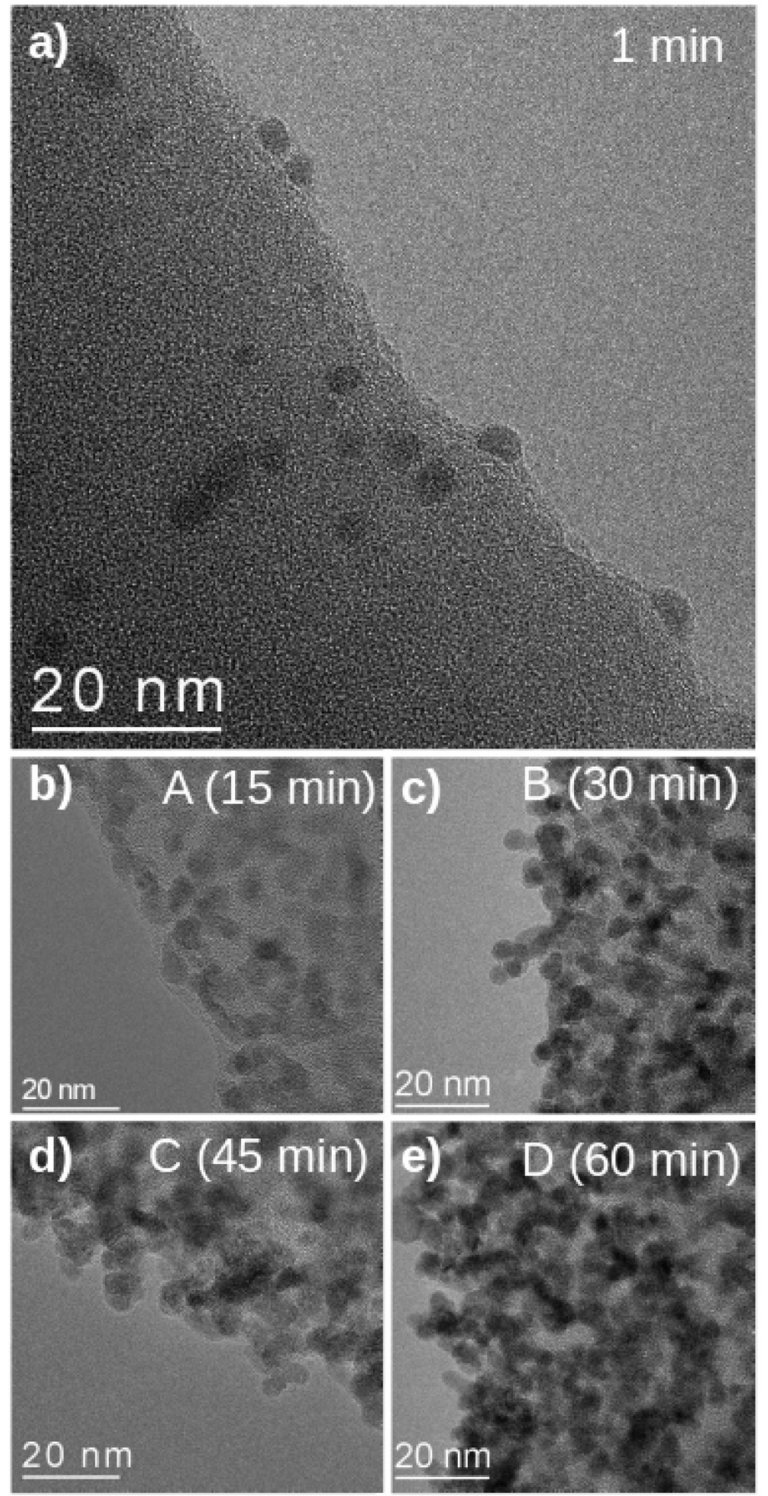

FIG. 1. HR-TEM micrographs of (a) single Pd clusters by a 1-min deposition, (b) a percolating network of clusters after a 15-min deposition, (c) island growth after a 30-min deposition and the formation of a thin film after a (d) 45-min and (e) 60-min deposition. sectional area of $13 \mathrm{~nm}^{2}$. The procedure for determination of the total volume of the palladium confined in the samples is described elsewhere. ${ }^{35}$ The volume of Pd deposited for $1 \mathrm{~min}$ is estimated to be $(1.5 \pm 0.3) \times 10^{-8} \mathrm{~cm}^{3}$. By varying the deposition time, the volume of the palladium confined in the analyzed samples could be adjusted, as the deposited volume is linearly dependent on deposition time. In this work, samples with four different volumes of palladium were analyzed (see Table II).

Cluster film formation depends on the cluster energy and size and on substrate properties. ${ }^{9}$ The palladium cluster film growth follows Stranski-Krastanov, layer-plus-island, type of growth. ${ }^{38}$ After a 15-min deposition [Fig. 1(b)], a percolating network of monolayer of Pd clusters is formed. A change in island growth is apparent after 30-min deposition which leads to surface coarsening. The resulting film morphology after 60-min deposition is porous consisting networks of percolating Pd clusters, as can be seen from the HR-TEM images. More details regarding the morphology can be found in the supplementary material.

Magnetization measurements were performed on all samples (Table II), but no magnetic signal could be obtained after 1 min deposition. Bulk Pd was also measured in order to have a reference sample. The results can be found in the supplementary material.

Figure 2 shows magnetization of the deposited nanoparticle samples. The experimental uncertainty in the $\mathrm{m}(\mathrm{H})$ measurements was $\sim 5 \%$. From the $\mathrm{M}-\mathrm{H}$ curves (Fig. 2) taken at various temperatures, coercivities, and remanence are extracted and plotted in Fig. 3. The hysteretic behaviour observed in the $\mathrm{M}-\mathrm{H}$ curves clearly supports a ferromagnetic spin ordering in the measured samples. We note that the magnetization curve consists of the saturated ferromagnetic component and the paramagnetic one. According to the previous studies, ${ }^{10,22}$ this corresponds to the coexistence of ferromagnetism and superparamagnetism in Pd-cluster films. The large variation visible in the hysteresis loops of the samples is related to the proportion of superparamagnetic nanoclusters in the films. ${ }^{39}$ The thick 60-min deposited films behave more consistently as film growth and the resulting morphology reaches a steady state. The error bars are within the used symbols in Fig. 2, thereby the hysteresis can unambiguously be identified at all temperatures up to $400 \mathrm{~K}$.

TABLE II. Summary of the samples showing the total volume of Pd confined in them and the deposition time.

\begin{tabular}{lccc}
\hline \hline Sample & Symbol & $\begin{array}{c}\text { Deposition time } \\
(\mathrm{min})\end{array}$ & $\begin{array}{c}\text { Volume } 10^{-8} \\
\left(\mathrm{~cm}^{3}\right)\end{array}$ \\
\hline A (A.1/A.2) & $\begin{array}{c}\text { Open square/ } \\
\text { closed blue square } \\
\text { Open circle/ } \\
\text { B (B.1/B.2) }\end{array}$ & 15 & $1.5 \pm 0.3$ \\
C (C.1/C.2) & $\begin{array}{c}\text { Open triangle/ } \\
\text { closed green triangle } \\
\text { Open diamond/ }\end{array}$ & 40 & $2.3 \pm 0.5$ \\
D (D.1/D.2) & $\begin{array}{c}\text { Oped rircle } \\
\text { closed orange diamond }\end{array}$ & 60 & $6.6 \pm 1.5$ \\
\hline \hline
\end{tabular}



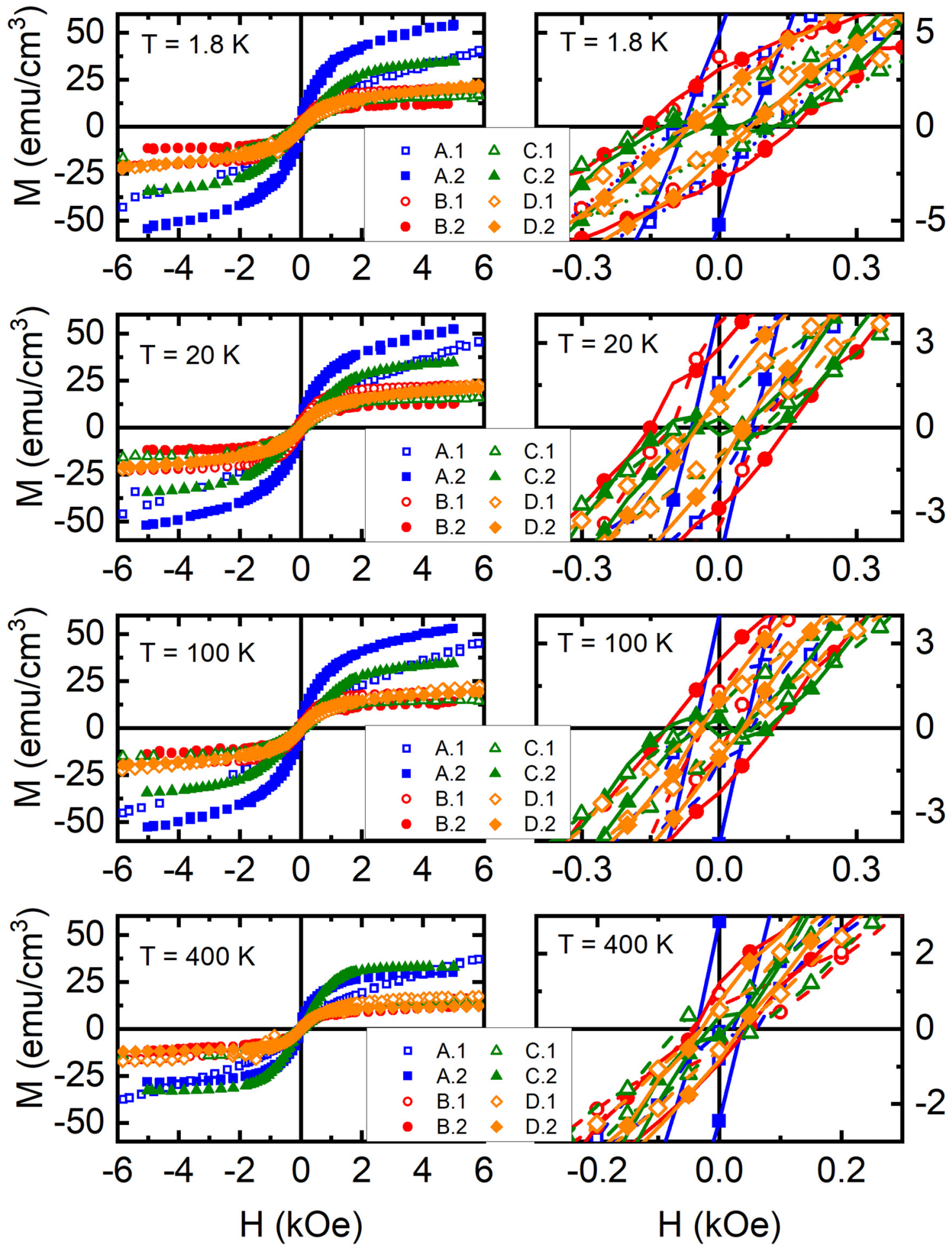

FIG. 2. Magnetization as a function of magnetic field measured at 1.8, 20,100, and $400 \mathrm{~K}$. In the left column, the full range measurements of all of the samples at a given temperature are shown. In the right column, zoomed graphs highlighting the remanence and coercivity are shown. In the supplementary material, the zoomed graphs are shown separately for each deposition time $(\mathrm{A}=15 \mathrm{~min}, \mathrm{~B}=30 \mathrm{~min}, \mathrm{C}=45 \mathrm{~min}$, and $\mathrm{D}=60 \mathrm{~min})$.

From the M-H curves at temperatures ranging from $1.8 \mathrm{~K}$ to $400 \mathrm{~K}$, volume magnetizations were extracted and the values for both extremities are provided in Table III. From volume magnetizations, the magnetic moments could be deduced and are shown in Fig. 4. These values are smaller than the obtained experimental values for Pd nanoparticles produced in vacuum ${ }^{10}$ and the reported theoretical values. ${ }^{32}$ This implies that the surface magnetization of our Pd cluster films is suppressed by oxidation in ambient atmosphere but not in the same extent as has been reported for Pd clusters after $\mathrm{O}_{2}$ gas exposure.

The magnetization-temperature dependence of the deposited nanoparticle samples is presented in Fig. 5. After cooling to the terminal temperature of $\sim 1.8 \mathrm{~K}$ in zero magnetic field, magnetization was measured as a function of temperature up to $\sim 400 \mathrm{~K}$ in the applied magnetic fields (ZFC) 


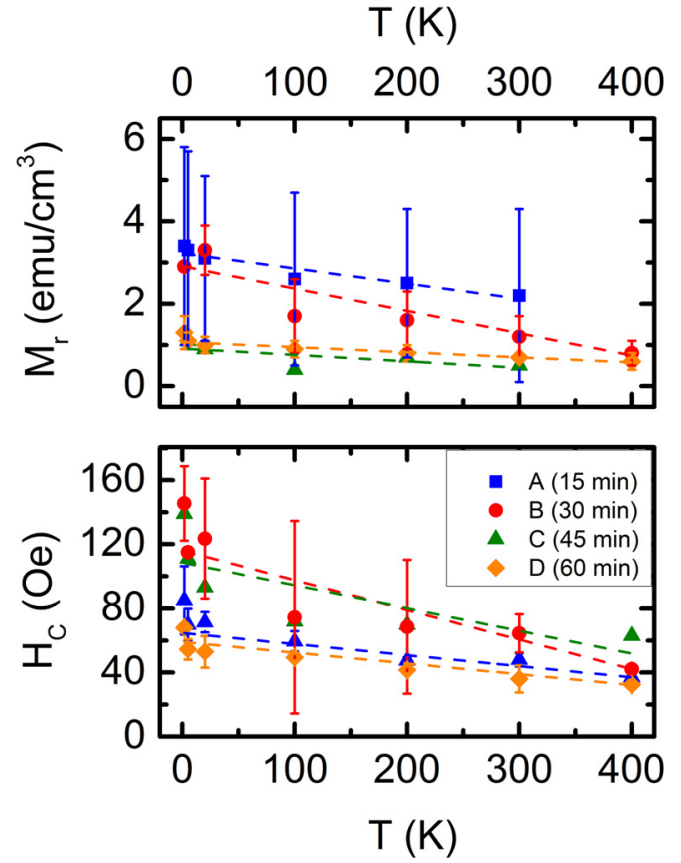

FIG. 3. Average remanence $\left(\mathrm{M}_{r}\right)$ and coercivity $\left(\mathrm{H}_{C}\right)$ for the samples obtained by using different deposition times.

of 50,150, and $300 \mathrm{Oe}$. After this, the measurements continued while the sample was cooled back to the terminal temperature (FC). The measured magnetization was found to exhibit irreversibility between ZFC and FC branches in all applied fields (see Fig. 5). As can be seen, after cooling in zero field, the magnetization goes through a broad maximum spanning from cryogenic temperatures up to $\sim 400 \mathrm{~K}$. The temperature at which the curves split corresponds to the onset of the irreversibility.

The previous studies have reported an increase in the magnetization with decreasing temperature below $20 \mathrm{~K} .^{11,14,26}$ The increase is believed to be caused by bulk like properties emerging with increasing film thickness. The same behavior can also be seen in the case of our bulk sample (see the supplementary material). However, a slight increase can be seen only for samples C.1 and D.

From our results, it can be seen that palladium nanoclusters exhibit ferromagnetic behavior combined with film thickness dependent small (super)paramagnetic contribution

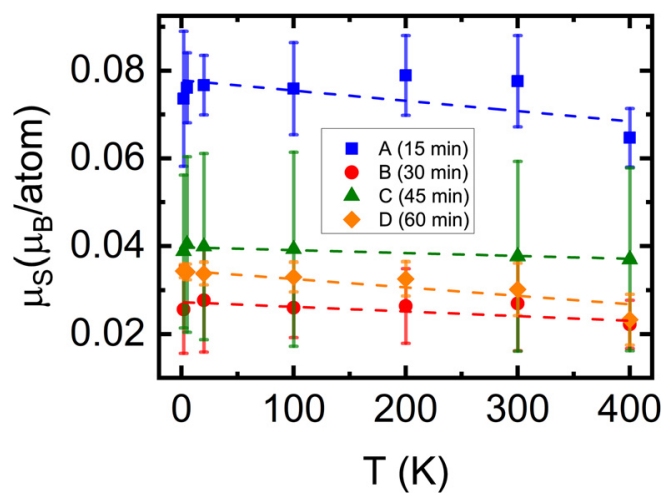

FIG. 4. Average volume magnetic moment corresponding to different deposition-times.

(see Fig. 2). Furthermore, thin cluster films at the limit of (approximately) single layer coverage exhibit the highest magnetization. The magnetization strength does not decrease systematically with respect to film thickness (see Table III), as magnetization of 30-min films is weaker compared to films obtained with 45-min deposition time.

By analysing the magnetization (Fig. 2) of the deposited nanoparticle samples, additional information regarding superparamagnetic (SP) and single domain (SD) (ferro)magnetism of cluster films can be acquired. ${ }^{39}$ The difference between the descending and ascending parts of the hysteresis $(\Delta \mathrm{M})$ and its derivatives $\mathrm{d} / \mathrm{dH}[\Delta M]$ are shown in Fig. 6. The shape of $\Delta \mathrm{M}$ for the $15 \mathrm{~min}$ deposition [Fig. 6(a)] is due to "wasp-waist"-hysteresis. The slope with a small hump around $0.5 \mathrm{kOe}$ causes a double peak in the $\mathrm{d} / \mathrm{dH}[\Delta M]$ plot [Fig. 6(e)], this corresponds to SD + SP magnetism with two sets of coercivities. The $\Delta \mathrm{M}$ plot for the $30 \mathrm{~min}$ deposition [Fig. 6(b)] originates from a combination of "potbelly-" and "wasp-waist"-types of behavior. ${ }^{39}$ The derivative d/dH[ $\left.\Delta M\right]$ [Fig. 6(f)] shows two widely separated peaks, with a weak one between them. The changing hysteresis from "waspwaist" to "potbelly" shape is due to an increase in small magnetic clusters with respect to larger ones found for the 15 min deposition.

The shape of $\Delta \mathrm{M}$ for the $45 \mathrm{~min}$ deposition is characteristic for "potbellied" hysteresis [Fig. 6(c)]. The number of small magnetic clusters dominates, while suppressing the "waspwaist" part (in comparison to the $30 \mathrm{~min}$ deposition). The

TABLE III. Summary of our results.

\begin{tabular}{|c|c|c|c|c|c|c|c|}
\hline Pd form & $\begin{array}{l}\text { Nanoparticle } \\
\text { diameter }(\mathrm{nm})\end{array}$ & Oxidation & $\begin{array}{c}\mathrm{T} \\
(\mathrm{K})\end{array}$ & $\begin{array}{l}\mu_{S} \times 10^{-3} \\
\left(\mu_{B} / \text { atom }\right)\end{array}$ & $\begin{array}{c}\mathrm{M}_{S} \\
\left(\mathrm{emu} / \mathrm{cm}^{3}\right)\end{array}$ & $\begin{array}{c}\mathrm{M}_{R} \\
\left(\mathrm{emu} / \mathrm{cm}^{3}\right)\end{array}$ & $\begin{array}{l}\mathrm{H}_{C} \\
(\mathrm{Oe})\end{array}$ \\
\hline \multirow{9}{*}{$\begin{array}{l}\text { NP agglomerates } \\
\text { prepared by } \\
\text { gas evaporation }\end{array}$} & $4.1 \pm 1.6$ & Exposed to ambient conditions & & & & & \\
\hline & $\mathrm{V}_{A}=2.3 \pm 0.5$ & & 1.8 & $74 \pm 15$ & $46 \pm 10$ & $3.4 \pm 2.4$ & $85 \pm 21$ \\
\hline & & & 400 & $65 \pm 6$ & $42 \pm 4$ & $2.2 \pm 2.1(300 \mathrm{~K})$ & $48 \pm 4(300 \mathrm{~K})$ \\
\hline & $\mathrm{V}_{B}=4.5 \pm 1.0$ & & 1.8 & $26 \pm 10$ & $16 \pm 6$ & $2.9 \pm 0.0$ & $150 \pm 23$ \\
\hline & & & 400 & $22 \pm 5$ & $14 \pm 4$ & $0.8 \pm 0.3$ & $42 \pm 3$ \\
\hline & $\mathrm{V}_{C}=6.6 \pm 1.5$ & & 1.8 & $39 \pm 17$ & $24 \pm 11$ & $1.5^{\mathrm{a}}$ & $140^{\mathrm{a}}$ \\
\hline & & & 400 & $37 \pm 21$ & $23 \pm 13$ & $0.48^{\mathrm{a}}$ & $63^{\mathrm{a}}$ \\
\hline & $\mathrm{V}_{D}=9.0 \pm 2.1$ & & 1.8 & $34 \pm 2$ & $22 \pm 1$ & $1.3 \pm 0.4$ & $68 \pm 3$ \\
\hline & & & 400 & $23 \pm 6$ & $15 \pm 4$ & $0.65 \pm 0.16$ & $33 \pm 1$ \\
\hline
\end{tabular}

${ }^{\mathrm{a} O n l y ~ C .1 .}$ 

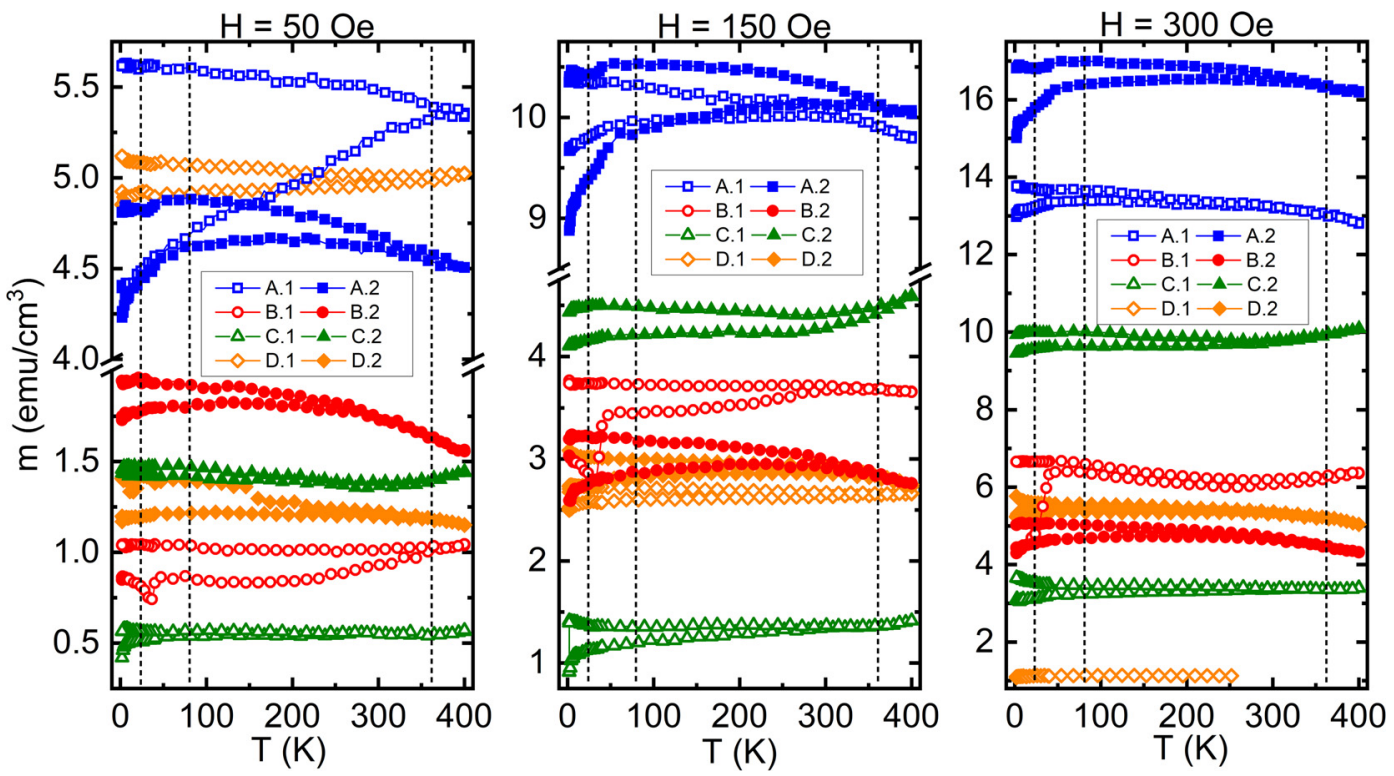

FIG. 5. Temperature dependence of magnetization in magnetic fields of 50, 150, and 300 Oe for each deposition time $(\mathrm{A}=15 \mathrm{~min}, \mathrm{~B}=30 \mathrm{~min}, \mathrm{C}=45 \mathrm{~min}$, and $\mathrm{D}=60 \mathrm{~min}$ ). The dashed vertical lines correspond to characteristic magnetization behaviour for bulk $\mathrm{Pd}$ at temperatures of $360 \mathrm{~K}$ (the end of magnetization change), $\mathrm{T}_{m} \approx 80 \mathrm{~K}$ (local magnetization maximum), and $22.5 \mathrm{~K}$ (local magnetization minimum). See supplementary material for more details.

majority of the magnetic clusters have a single coercivity value related to the pronounced peak around $0.5 \mathrm{kOe}$ [Fig. $6(\mathrm{~g})]$. The $\mathrm{d} / \mathrm{dH}[\Delta M]$ plot is simplified to that of the $15 \mathrm{~min}$ deposition, with small convolution of peaks closer to the origin. $\Delta \mathrm{M}$ for the $60 \mathrm{~min}$ deposition [Fig. $6(\mathrm{~d})$ ] is less defined to a certain magnetization scheme, due to an apparent convolution of the second peak in $\mathrm{d} / \mathrm{dH}[\Delta M]$ plot close to the origin [Fig. 6(h)]. The merging of the first and second peaks corresponds to the tendency of SP clusters, with single valued coercivity, to transform to a single domain magnetization.

We suggest here that the magnetization of a Pd cluster film depends on the deposition parameters which determine the Pd cluster size and the internal structure and morphology of the resulting film. The variation in the observed magnetization can neither be explained by differences in lattice constants nor cluster crystal phases, as the selected area diffraction patterns are similar for the 15-min and 45-min deposited Pd cluster films (supplementary material). In the initial formation of the cluster film (15 min deposition), the coercivity values (by $\mathrm{d} / \mathrm{dH}[\Delta M]$ ) are related to two possible cluster agglomeration configurations: cluster layers and layers with small pile-ups of clusters (islands), which can be seen in the HR-TEM micrographs (Fig. 1). As the cluster deposition time doubled, the magnetization weakens and can be understood by the reduced surface to volume ratio.
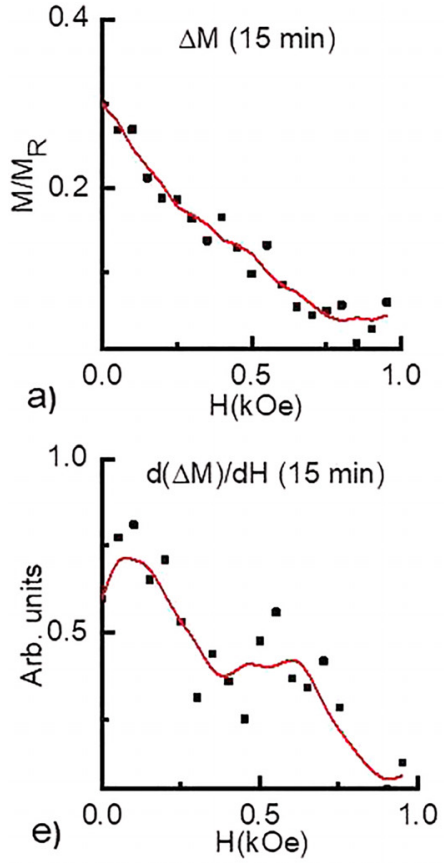
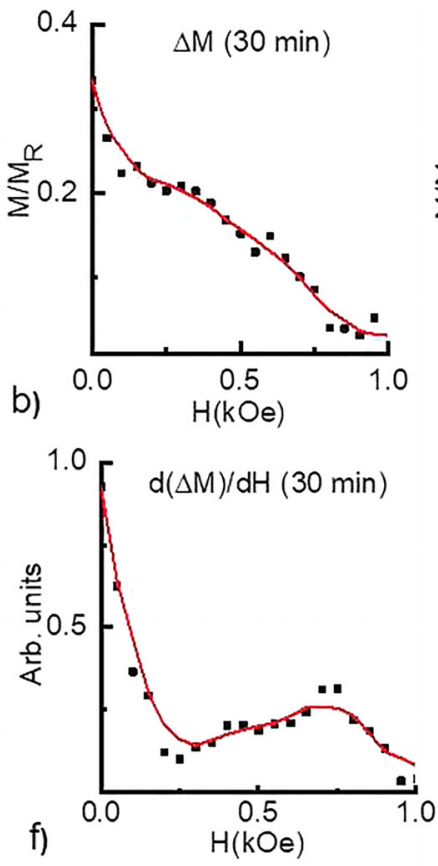
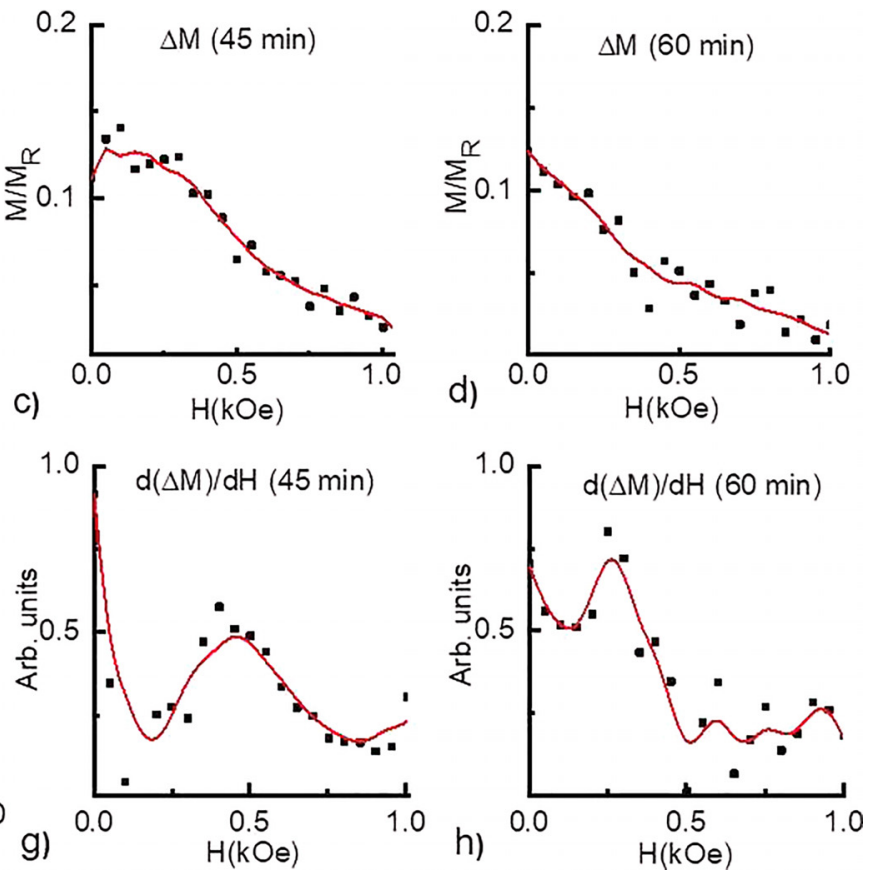

FIG. 6. The $\Delta \mathrm{M}$ and its derivative $\mathrm{d} / \mathrm{dH}[\Delta M]$ measured at $20 \mathrm{~K}$. The lines in the figure correspond to 5-point averaging of the data. 
If a simple stacking of clusters into a porous percolation network is assumed, then the retained magnetization for the 45 and $60 \mathrm{~min}$ films is not as expected, when compared to the magnetization of the $30 \mathrm{~min}$ film. An impact of Pd clusters with a smooth Pd monolayer ( $30 \mathrm{~min}$ deposition) will result in higher local heating peaks, than an impact with rough Pd cluster agglomerates (45 and $60 \mathrm{~min}$ deposition) or with a plastic surface, having lower adhesion than $\mathrm{Pd}$ ( 15 min deposition). ${ }^{40}$ Increased impact energy is due to adhesion acceleration that depends on the impact area between the cluster and the surface. Thereby, film growth becomes more complex as impact energy of the impinging Pd clusters increases. The full coalescence of nanoclusters on a Pd substrate leads to a significant surface energy release and heating up of the merging Pd clusters in addition. The average impact energy of $0.16 \mathrm{eV} / \mathrm{atom}$, for the Pd clusters in this work, is within the threshold range of grain boundary annihilation for $\mathrm{Cu}$ clusters. ${ }^{40,41}$ The same threshold can also be assumed to be valid for Pd cluster boundaries, as the difference in cohesive energies for these two systems is within $10 \%$.

It should be noted that all of the samples deposited for 30, 45, and $60 \mathrm{~min}$ have a dense Pd cluster layer. Samples deposited for 45 and $60 \mathrm{~min}$ do, however, have a higher volume of a porous layer, which dominates the magnetization properties. The film growth modes, initial layer by layer, and sequent island growth yield roughly two different film morphologies, with a relatively dense interface and a porous layer on top of it. This is reflected in the magnetization properties with increasing Pd film thickness. The strongest coercive fields are found for the films deposited for 30 and $45 \mathrm{~min}$, having the most anisotropic morphology. The formation of a continuous porous layer increases the isotropy, leading to a reduction in the coercive field, as can be seen for the sample deposited for $60 \mathrm{~min}$.

\section{CONCLUSIONS}

We have investigated how the ferromagnetic behavior of bare palladium nanoclusters changes with respect to range and degree of interactions, starting from a network of clusters evolving to a film with porous morphology. The morphology of the samples was analyzed by HR-TEM micrographs. A SQUID was used to determine the hysteresis with temperature dependent saturation magnetization, remanence, coercivity, as well as the magnetization temperature dependence. Based on the acquired results, we propose that the magnetization of Pd cluster networks and films depends on the growth properties determining the variations in the $\mathrm{Pd}$ cluster structures and resulting film morphologies.

\section{SUPPLEMENTARY MATERIAL}

See supplementary material for a more detailed description of the morphology of Pd clusters. The magnetization measurements of bulk Pd, zoomed graphs on the magnetization as a function of magnetic field separately for each deposition time, as well as the diffraction patterns for the 15 and 45-min deposited Pd cluster films are shown in the supplementary material.

\section{ACKNOWLEDGMENTS}

The doctoral program in Materials Research and Nanosciences (MATRENA) of Helsinki University is acknowledged for financial support. Funding from the Finnish Center of Excellence in Atomic Layer Deposition (Academy of Finland) is gratefully acknowledged. This research made use of the OtaNano-Low Temperature Laboratory infrastructure of Aalto University.

${ }^{1}$ E. Hüger and K. Osuch, "Pd bonded on $\mathrm{Nb}(001)$ : Dependence of noble metal and ferromagnetic characteristics on film thickness," Phys. Rev. B 72, 085432 (2005).

${ }^{2}$ S. Sakuragi, T. Sakai, S. Urata, S. Aihara, A. Shinto, H. Kageshima, M. Sawada, H. Namatame, M. Taniguchi, and T. Sato, "Thickness-dependent appearance of ferromagnetism in $\operatorname{Pd}(100)$ ultrathin films," Phys. Rev. B 90, 054411 (2014).

${ }^{3}$ S. Ghosh, S. Tongay, A. F. Hebard, H. Sahin, and F. M. Peeters, "Ferromagnetism in stacked bilayers of $\mathrm{Pd} / \mathrm{C}_{60}$," J. Magn. Magn. Mater. 349, 128-134 (2014).

${ }^{4}$ S. Sakuragi, "Ferromagnetism in Pd(100) ultrathin films enhanced by distortion," Phys. Procedia 75, 1167-1171 (2015).

${ }^{5}$ A. Niklasson, S. Mirbt, H. Skriver, and B. Johansson, "Quantum-wellinduced ferromagnetism in thin films," Phys. Rev. B 56, 3276-3280 (1997).

${ }^{6} \mathrm{~S}$. Blügel, "Magnetism of $4 \mathrm{D}$ and $5 \mathrm{D}$ transition metal adlayers on $\operatorname{Ag}(001)$ : Dependence on the adlayer thickness," Phys. Rev. B 51, 2025-2028 (1995).

${ }^{7}$ S. C. Hong, J. I. Lee, and R. Wu, "Ferromagnetism in Pd thin films induced by quantum well states," Phys. Rev. B 75, 172402 (2007).

${ }^{8}$ X. Teng, W. Q. Han, W. Ku, and M. Hücker, "Synthesis of ultrathin palladium and platinum nanowires and a study of their magnetic properties," Angew. Chem. Int. Ed. 47, 2055-2058 (2008).

${ }^{9}$ A. Delin, E. Tosatti, and R. Weht, "Magnetism in atomic-size palladium contacts and nanowires," Phys. Rev. Lett. 92, 057201 (2004).

${ }^{10}$ T. Shinohara, T. Sato, and T. Taniyama, "Surface ferromagnetism of Pd fine particles," Phys. Rev. Lett. 91, 197201 (2003).

${ }^{11}$ B. Sampedro, P. Crespo, A. Hernando, R. Litrán, J. C. Sánchez López, C. López Cartes, a Fernandez, J. Ramírez, J. González Calbet, and M. Vallet, "Ferromagnetism in fcc twinned $2.4 \mathrm{~nm}$ size Pd nanoparticles," Phys. Rev. Lett. 91, 237203 (2003).

${ }^{12}$ L. Vitos, B. Johansson, J. Kollár, and H. L. Skriver, "Size-dependent paramagnetic-ferromagnetic phase transition in palladium clusters," Phys. Rev. B 62, 10046 (2000).

${ }^{13}$ S. S. Alexandre, E. Anglada, J. M. Soler, and F. Yndurain, "Magnetism of two-dimensional defects in Pd: Stacking faults, twin boundaries, and surfaces," Phys. Rev. B 74, 054405 (2006).

${ }^{14} \mathrm{Y}$. T. Jeon and G. H. Lee, "Magnetism of the fcc Rh and Pd nanoparticles," J. Appl. Phys. 103, 094313 (2008).

${ }^{15}$ E. C. Stoner, "Collective electron ferromagnetism. II. Energy and specific heat," Proc. R. Soc. A 169, 339-371 (1939).

${ }^{16}$ M. M. Sigalas and D. A. Papaconstantopoulos, "Calculations of the total energy, electron-phonon interaction, and Stoner parameter for metals," Phys. Rev. B 50, 7255-7261 (1994).

${ }^{17}$ Y. Oba, T. Sato, and T. Shinohara, "Ferromagnetism induced by strains in Pd nanoparticles," Phys. Rev. B 78, 224417 (2008).

${ }^{18}$ S. Aihara, H. Kageshima, T. Sakai, and T. Sato, "First-principles study of charging effect on magnetism of Pd (100) ultrathin films," J. Appl. Phys. 112, 073910 (2012).

${ }^{19}$ T. Taniyama, E. Ohta, and T. Sato, "Observation of $4 \mathrm{~d}$ ferromagnetism in free-standing Pd fine particles,” Europhys. Lett. 38, 195-200 (1997).

${ }^{20}$ T. Taniyama, E. Ohta, and T. Sato, "Ferromagnetism of Pd fine particles," Physica B 237-238, 286-288 (1997).

${ }^{21}$ T. Shinohara, T. Sato, and T. Taniyama, "Ferromagnetism of gasevaporated Pd fine particles in mesoscopic size," J. Magn. Magn. Mater. 272-276, 2003-2004 (2004).

${ }^{22}$ Y. Oba, T. Sato, and T. Shinohara, "Gas adsorption on the surface of ferromagnetic Pd nanoparticles," e-J. Surf. Sci. Nanotechnol. 4, 439-442 (2006).

${ }^{23}$ B. Sampedro, T. C. Rojas, A. Fernández, and A. Hernando, "Palladium nanoparticles obtained by mechanical milling," Phys. Status Solidi 203, 1201-1205 (2006). 
${ }^{24}$ Y. Oba, H. Okamoto, T. Sato, T. Shinohara, J. Suzuki, T. Nakamura, T. Muro, and H. Osawa, "X-ray magnetic circular dichroism study on ferromagnetic Pd nanoparticles," J. Phys. D: Appl. Phys. 41, 134024 (2008).

${ }^{25}$ T. Okamoto, H. Maki, Y. Oba, S. Yabuuchi, T. Sato, and E. Ohta, "Electrical detection of ferromagnetism in Pd nanoparticles by magnetoresistance measurement," J. Appl. Phys. 106, 023908 (2009).

${ }^{26}$ M. S. Seehra, J. D. Rall, J. C. Liu, and C. B. Roberts, "Core-shell model for the magnetic properties of Pd nanoparticles," Mater. Lett. 68, 347-349 (2012).

${ }^{27}$ F. Aguilera-Granja, A. Vega, J. Rogan, W. Orellana, and G. García, "Magnetic properties of Pd atomic clusters from different theoretical approaches," Eur. Phys. J. D 44, 125-131 (2007).

${ }^{28}$ V. L. Moruzzi and P. M. Marcus, "Magnetism in fcc rhodium and palladium," Phys. Rev. B 39, 471-474 (1989).

${ }^{29} \mathrm{H}$. Chen, N. Brener, and J. Callaway, "Electronic structure, optical and magnetic properties of fcc palladium," Phys. Rev. B 40, 1443-1449 (1989).

${ }^{30}$ P. K. Kulriya, B. R. Mehta, D. C. Agarwal, P. Kumar, S. M. Shivaprasad, J. C. Pivin, and D. K. Avasthi, "Giant enhancement in ferromagnetic properties of Pd nanoparticle induced by intentionally created defects," J. Appl. Phys. 112, 014318 (2012).

${ }^{31}$ H. M. Song, J. I. Zink, and N. M. Khashab, "Investigating unexpected magnetism of mesoporous silica-supported Pd and PdO nanoparticles," Chem. Mater. 27, 29-36 (2015)

${ }^{32}$ B. V. Reddy, S. N. Khanna, and B. I. Dunlap, "Giant magnetic moments in 4d clusters," Phys. Rev. Lett. 70, 3323-3326 (1993).
${ }^{33}$ J. Bansmann, S. Baker, C. Binns, J. Blackman, J. Bucher, J. Dorantesdavila, V. Dupuis, L. Favre, D. Kechrakos, and A. Kleibert, "Magnetic and structural properties of isolated and assembled clusters," Surf. Sci. Rep. 56, 189-275 (2005).

${ }^{34}$ J. F. Löffler, H.-B. Braun, and W. Wagner, "Magnetic correlations in nanostructured ferromagnets," Phys. Rev. Lett. 85, 1990-1993 (2000).

${ }^{35}$ A. Venäläinen, P. Jalkanen, V. Tuboltsev, K. Meinander, A. Savin, and J. Räisänen, "Ferromagnetism in bare gold nanoagglomerates produced by nanocluster deposition," J. Magn. Magn. Mater. 454, 57-60 (2018).

${ }^{36}$ Clusters of Atoms and Molecules, Springer Series in Chemical Physics, edited by H. Haberland (Springer, Berlin, Heidelberg, 1994), Vol. 52.

${ }^{37}$ I. Yamada and N. Toyoda, "Recent advances in R\&D of gas cluster ion beam processes and equipment," Nucl. Instrum. Methods Phys. Res. Sect. B 241, 589-593 (2005).

${ }^{38}$ A. Dollinger, E. J. Park, C. H. Strobel, H. Bleuel, A. Marsteller, H. O. Seo, Y. D. Kim, and G. Ganteför, "Thin films of size-selected Mo clusters: Growth modes and structures," Phys. Chem. Chem. Phys. 17, 20873-20881 (2015).

${ }^{39}$ L. Tauxe, T. A. T. Mullender, and T. Pick, "Potbellies, wasp-waists, and superparamagnetism in magnetic hysteresis," J. Geophys. Res. Solid Earth 101, 571-583, https://doi.org/10.1029/95JB03041 (1996).

${ }^{40} \mathrm{~K}$. Meinander, K. Nordlund, and J. Keinonen, "Inherent surface roughening as a limiting factor in epitaxial cluster deposition," Nucl. Instrum. Methods Phys. Res. Sect. B 228, 69-74 (2005).

${ }^{41}$ V. N. Popok, I. Barke, E. E. B. Campbell, and K.-H. Meiwes-Broer, "Cluster-surface interaction: From soft landing to implantation," Surf. Sci. Rep. 66, 347-377 (2011). 